\title{
A comparative study on nitrogen-concentration dynamics in surface water in a heterogeneous landscape
}

\author{
Liding Chen · Bojie Fu · Shurong Zhang · Jun Qiu · Xudong Guo · Fulin Yang
}

\begin{abstract}
With point-source pollution controlled effectively, nonpoint-source pollution, especially that resulting from agricultural land, has become the main factor affecting surface water. Much attention has been focused on the impact of fertilizer and pesticide application, wastewater irrigation, and land management on pollutant transport. However, landscape pattern also plays an important role in pollutant transport and detention. Landscape types may be classified into two parts: "source" and "sink" landscapes, based on their functions in pollutant transport and detention. As a major contributor to eutrophication of waterbodies, nitrogen loss with runoff has received particular attention when studying nonpoint-source pollution. In this study, four watersheds in the upper parts of the Yuqiao Reservoir Basin, Zuihua, Hebei Province, China, were chosen in order to study the relationship between landscape pattern and nitrogen-concentration dynamics. The results indicate that (1) nitrogen concentration in surface water within different seasons in the rainfall-normal year is higher than that in the rainfall-deficit year and (2) the variation of nitrogen concentration within different seasons in the rainfall-deficit year is smaller compared with that in the rainfall-normal year in which two types of seasonal variation on nitrogen concentration are presented. The first variation occurs when nitrogen concentration is lowest in the dry season, and rises rapidly from the dry season to rainy season and then declines quickly from the rainy season to mean-flow
\end{abstract}

Received: 28 September 2001 / Accepted: 21 January 2002 Published online: 19 March 2002

(C) Springer-Verlag 2002 season. This mainly occurs in those areas where most "source" landscapes are close to the monitored waterbody. The second variation occurs when nitrogen concentration is low in the dry season, increases rapidly in the rainy season but does not reach its peak value until the mean flow season. The second variation occurs in those areas where "source" landscape types are spread over the whole watershed. There is no clear relationship between watershed shape, relative importance of landscape types, and nitrogen concentration; however, the spatial distribution of "source" and "sink" landscape types in the watershed has a strong impact on the nitrogen concentration in surface water.

Keywords Nonpoint-source pollution . "Source" and "sink" landscape · Nitrogen concentration · Heterogeneous landscape $\cdot$ Landscape pattern

\section{Introduction}

Nonpoint-source pollution, in contrast to point-source pollution, arises from sources that are normally associated with agricultural, silvicultural, and human activities in a watershed (Alm 1990; Line and others 1994, 1998; He and others 1998; Chen and Fu 2000; Istvanovics and Somlyody 2001). Nonpoint-source pollutants, such as nutrients, pesticides, heavy metals, and solid contaminants, are transported from the land by atmospheric, surface-water, and groundwater means. As its amount, sources, and geographical boundaries are difficult to identify, the process of nonpoint-source pollution is still unclear (Alm 1990; Troiano and others 1993; Line and others 1994, 1998; $\mathrm{He}$ and others 1998; Zhang and Zhuang 1998; Chen and Fu 2000; Heathwaite and others 2000; Stow and others 2001). With point-source pollution under control, nonpointsource pollution, especially agricultural nonpoint-source pollution, has become one of the dominant environmental issues. Nonpoint-source pollution comprises three aspects: pollutant sources, sinks, and transport. With arable land declining and population growing, the increasing demand on food provision will lead to increases in fertilizer and pesticide applications. This implies that controlling nonpoint-source pollution from the sources will be very 
difficult. The retention of pollutants by soils and landscapes, such as riparian forests (Sliva and Williams 2001), wetlands, canals, and sedimentation ponds, etc., to some extent could reduce the risk of developing nonpointsource pollution (Knisel 1980; Peterjohn and Correll 1984; Yin and others 1993; Pearce and others 1997; Ebbert and Kim 1998; He and others 1998; Wang and others 1998; Fu and others 1999; Li Junran and others 2000; Li Xiuzhen and others 2001). If the effects of landscape on pollutant transport and retention are considered, landscape types may be classified into two groups: one is "source" and the other is "sink". The spatial distribution of these two kinds of landscape may affect the formation of nonpoint-source pollution (Ebbert and Kim 1998; Li Junran and others 2000; Chen and others 2001). It is of scientific significance to control nonpoint-source pollution, nutrient loss, and material transport, which may be achieved by studying the effect of landscape patterns on the origination and detention of nonpoint-source pollutants to seek a landscape ecosystem suitable for pollutant retention.

Since the source and process of nonpoint-source pollution are unclear (Nikolaidis and others 1998), geographic information system (GIS) and mathematical models have proved to be useful tools to simulate the effect of landscape pattern and land management on nonpoint-source pollution, or nutrient loss and transport (Gilliland 1987;

Leonard and others 1987; Young and others 1989; Heng and others 1998; Mankin and others 1999; Yan and Kahawita 2000; Leon and others 2001). In this study, water sampling in the field with GIS is used to focus the objectives on the seasonal characteristics of nonpoint-source pollution (particularly the nitrogen concentration in surface water) within heterogeneous landscapes at four typical watersheds, and the effects of watershed shape and landscape pattern on nitrogen concentration in surface water.

\section{Study area and methodology}

\section{The study area}

Yuqiao Reservoir Basin is located on the upper part of the Jiyun River $\left(39^{\circ} 56^{\prime}-40^{\circ} 23^{\prime} \mathrm{N}\right.$ and $\left.117^{\circ} 26^{\prime}-118^{\circ} 12^{\prime} \mathrm{E}\right)$ and covers parts of Hebei Province and Tianjin Metropolitan District with an area of $2,052 \mathrm{~km}^{2}$. This catchment is characterized by a temperate territorial semi-humid climate. Annual average temperature is $10.4-11.5^{\circ} \mathrm{C}$, and mean annual precipitation is $749 \mathrm{~mm}$, of which most occurs from July to August by rainstorm. The hilly regions above $500 \mathrm{~m}$ in the catchment account for $24.5 \%$ of the total area. Yuqiao Reservoir is an important regulation pool for extracting water from the Luan River for Tianjin's industrial, agricultural, and daily use. Eutrophication of Yuqiao Reservoir may induce some effects on human health in Tianjin, as well as on the water quality of Jiyun River and Bohai Sea (Wang and Guo 1999; Li Junran and others 2000). Zuihua county, located on the upper part of the Yuqiao Reservoir Basin, is a risk area for nonpointsource pollution, since a lot of the area is used for agricultural purposes. To avoid the effects of point-source pollution due to industrial activities, four typical watersheds in the upper hilly regions of the Yuqiao Reservoir Basin where agricultural activities are dominant and industrial activity is limited were selected as case study areas. In these watersheds, land-use/cover primarily consists of woodland, shrubland, grassland, orchard, chestnut land, and cropland. Cultivated crops are wheat, maize, peanut, potato, etc. Field surveys show that land management, fertilizer and pesticide application, and irrigation methods are almost the same for the same land-use type throughout the study area. However, among different land-use types (e.g., chestnut land, orchard and farmland) many differences exist. The location of the study area is shown in Fig. 1.

\section{Landscape analysis method}

Field mapping of land-use/cover was carried out in August 2000 using a topo-map of scale 1:50,000, based on a Landsat image (TM of 1997) interpretation, and then a digital land-use/cover map was derived by GIS. Primary attributes of four typical watersheds are displayed in Table 1. For further study of the relationship between landscape pattern and nonpoint-source pollution, the landscape types were classified into two categories: the "source" landscape, which contributes pollutants to nonpoint-source pollution, and includes cropland, orchards, and chestnut land, etc, and the "sink" landscape, which may retain pollutants, and includes dense woodland, sparse woodland, and grassland, etc. With the surface-water sampling site taken as the reference point, spatial distribution with regard to distance, slope degree, and relative elevation of these two landscape types were calculated, respectively. It is generally considered that the nearer the "source" landscape is to the monitoring waterbody, the larger the slope degree, and the smaller the relative elevation, the more it contributes to surface-water pollution; it is opposite for a "sink" landscape. The interrelationship between the spatial pattern of "source" and "sink" landscape and nonpoint-source pollution can be investigated. As small soil spatial variation exists in such a small study area, the effect of soil pattern on nonpoint-source pollution is ignored. However, it is quite different for different landscape types. Thus, standardization is necessary, and Eq. (1) is used when calculating the area of "source" and "sink" landscape types:

$f_{(i j)}^{\prime}=f_{(i j)}^{0} \times \omega_{(i j)}$

where $f^{\prime}{ }_{(i j)}$ is the standardized area of $i$ th landscape, $f^{0}{ }_{(i j)}$ is the actual area of $i$ th landscape types within different sections with regard to distance $(1 \sim 10 \mathrm{~m}, 10 \sim 20 \mathrm{~m}, 20 \sim 30 \mathrm{~m}$, $\ldots N-10 \sim N \mathrm{~m})$, slope degree $\left(1 \sim 2,2 \sim 3,3 \sim 4, \ldots 89 \sim 90^{\circ}\right)$ and relative elevation $(1 \sim 5 \mathrm{~m}, 5 \sim 10 \mathrm{~m}, 10 \sim 15 \mathrm{~m}, \ldots$ $N-5 \sim N \mathrm{~m}$ ), and $\omega_{i}$ is the weight of each landscape type compared to the reference landscape. For "source" landscapes, the weight is assigned by comparing fertilizer application with the reference landscape, "farmland", while the weight of the "sink" landscape types is assigned based on 

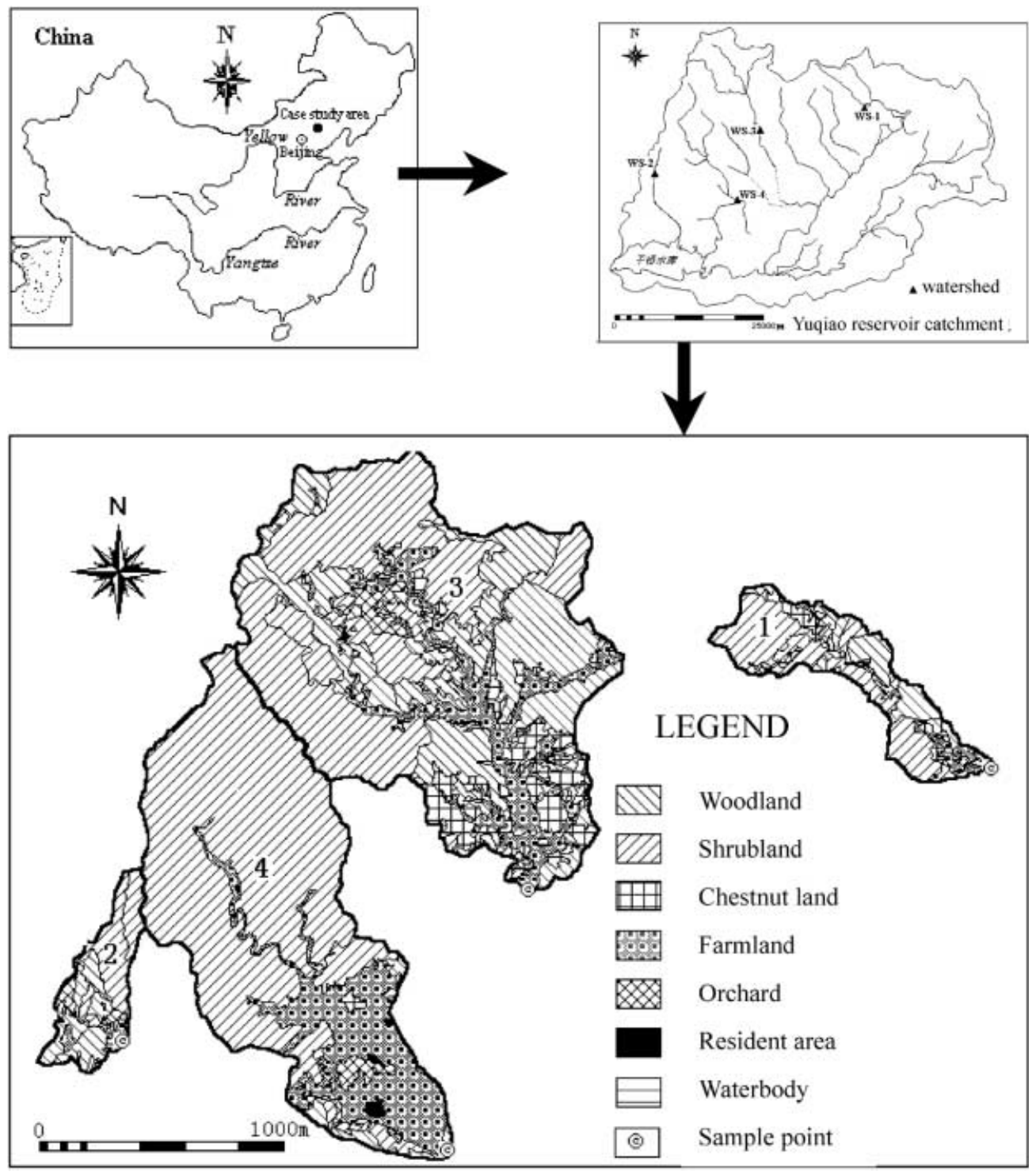

Fig. 1

Location of the study area and landscape types

nutrient reduction of each landscape type compared with the reference landscape, "dense woodland".

Additionally, landscape-diversity index ( $H$; O'Neill and others 1988; Fu 1995) and landscape-isolation index ( $F$; Pearce 1992; Chen and others 2001) were calculated, which are expressed by Eqs. (2) and (3), respectively:

$H=-\sum_{i=1}^{m} P c_{i} * \log \left(P c_{i}\right)$

$F_{i}=\left(A^{3 / 2}\right) /\left[2 A_{i} * n_{i}^{1 / 2}\right]$

where $H$ is the landscape-diversity index in a watershed, $P c_{i}$ is the area percentage of landscape type $i$, and $m$ is the total number of landscape types. $F_{i}$ is the isolation index of individual landscape type $i, A$ is the total area of the watershed, $A_{i}$ is the area of landscape type $i$, and $n_{i}$ is the patch number of landscape type $i$.

Landscape-isolation index to some extent reflects the importance of different landscape types in a watershed (Chen and others 2001). Its value is normally small and changeable. For comparing the importance of different landscape types, the relative-importance index $(Z)$ was introduced, which is derived from the reciprocal of the landscape-isolation index, and can be expressed as follows: $Z_{i}=F_{i}^{-1} / \sum\left(F_{i}^{-1}\right)$

where $Z_{i}$ and $F_{i}$ are the relative-importance index and the landscape-isolation index, respectively. The greater the $Z_{i}$ value, the more important in a watershed; otherwise, a smaller $Z_{i}$ means the landscape type is less important. To analyze the spatial distribution of landscape types within different watersheds, the ratio of two kinds of landscapes "source" and "sink" at the same level of area percentage was compared. A landscape-spatial-contrast index (SCI) was introduced as:

$S C I(i)=S(i) / H(i)$

where $S(i)$ and $H(i)$ are the distribution range of landscape "source" and "sink" at different area percentage levels 
Table 1

Landscape features of four typical watersheds

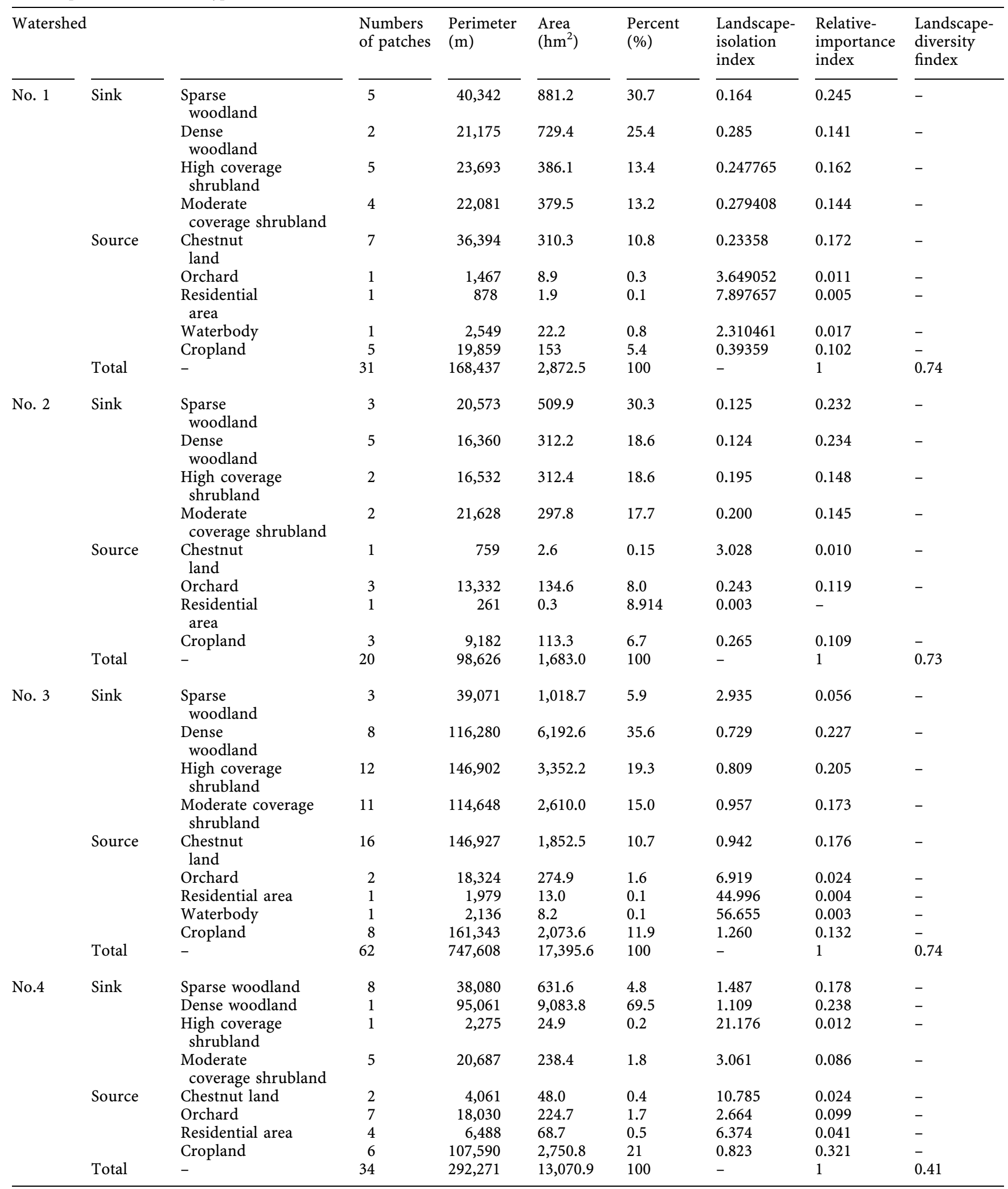


( $10 \% \ldots 100 \%)$, such as distance, slope degree, and relative elevation.

\section{Field sampling and analysis}

The water samples were collected at the artificial waterbody (small pond or reservoir) which is located in the outlet of four typical watersheds in the dry season (June), the rainy season (August), and the mean-flow season (October, when the runoff is between the flood season and dry season) from 1999 to 2000 . The water samples were taken using 1,000 $\mathrm{mL}$ poly-plastic containers and kept airproof for immediate analysis. The estimated indexes for pollutants include: $\mathrm{pH}$, chemical oxygen demand $\left(\mathrm{COD}_{\mathrm{Mn}}\right)$, biological oxygen demand $\left(\mathrm{BOD}_{5}\right)$, ammonium nitrogen (ammonium-N), nitric nitrogen (nitric-N), phosphates, and suspended solid particle (SSP). The $\mathrm{pH}$ was determined using a $\mathrm{pH}$ meter with a glass electrode method; $\mathrm{COD}_{\mathrm{Mn}}$ was determined by titration with acidic potassium permanganate; $\mathrm{BOD}_{5}$ was determined by titration, after treatment with a culture box using the dilution and inoculation method; ammonium-N was determined using Nessler's reagent colorimetry; nitric-N was determined by phenol disulfonic acid photometry; and phosphates were determined by ammonium molybdate spectrophotometer. The last three contaminants were all determined by Spectrophotometer-721 (the lower limit determined of phosphorus in the water samples is $0.025 \mathrm{mg} / \mathrm{L}$ ). The SSP was determined by turbidimeter with photometry. To emphasize the effect of landscape pattern on the nonpoint-source pollution in surface water, and considering the instability of different specific nitro-

Fig. 2

Comparison of the distribution of "source" landscape (I) and "sink" landscape (II) with distance, slope degree, and relative elevation in the four watersheds
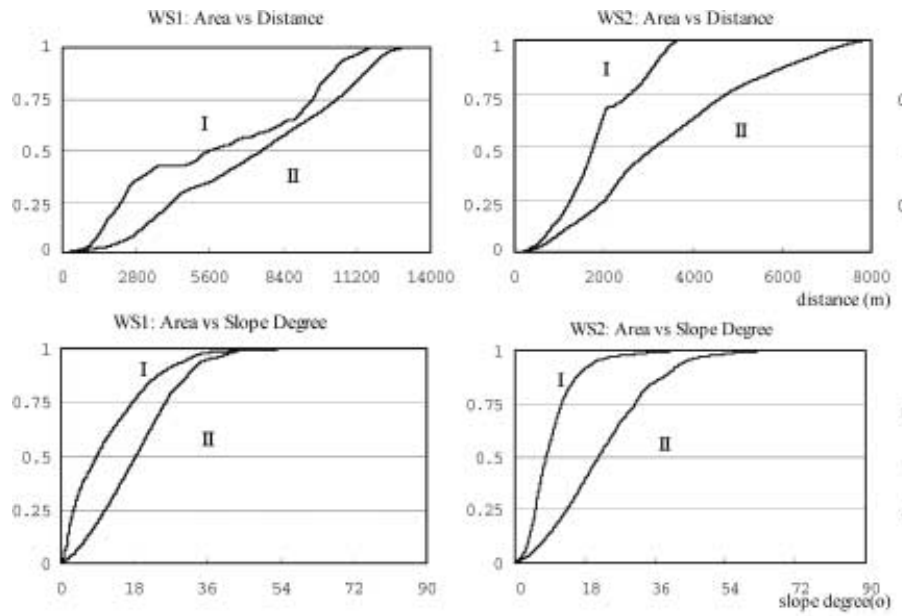

WSt: Area vs Relative Elevation
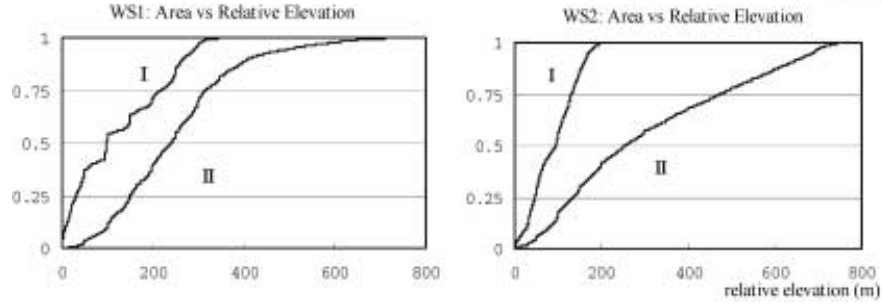

gen in water, total dissolved nitrogen (ammonium-N and nitric-N) was selected as the indicating index.

\section{Results}

\section{Watershed characteristics and relative landscape importance}

Among the four watersheds, watersheds 1 and 2 are long and narrow and their coverage is below $30 \mathrm{~km}^{2}$, while watersheds 3 and 4 have a large size with an area of more than $100 \mathrm{~km}^{2}$. Watershed 3 is a typical dendritic river system, while watershed 4 is in between a strip-shaped and a dendritic river system. Apart from a low landscapediversity index for watershed 4 (0.41), high landscapediversity indexes are found for the other three watersheds (Table 1). Further analysis indicates that "sink" landscape types play an important role in watersheds 1 and 2, and that some source-landscape types, such as chestnut land (0.172) and cropland (0.102) in watershed 1 , and orchard (0.119) and cropland (0.109) in watershed 2, also play an important role. In watershed 3, besides "sink" landscape types playing important roles, the relative-importance index of chestnut land and cropland is 0.176 and 0.132 , respectively, and these also play an important role. In watershed 4 , the relative-importance index of cropland $(0.321)$ is in the first position and it plays a decisive role.

\section{Spatial distribution of "source" and "sink" landscape types}

Figure 2 shows the cumulative area of "source" and "sink" landscape change with the three factors (distance, slope degree, and elevation) in watersheds 1 and 2. Both watersheds 1 and 2 are strip-shaped river systems with
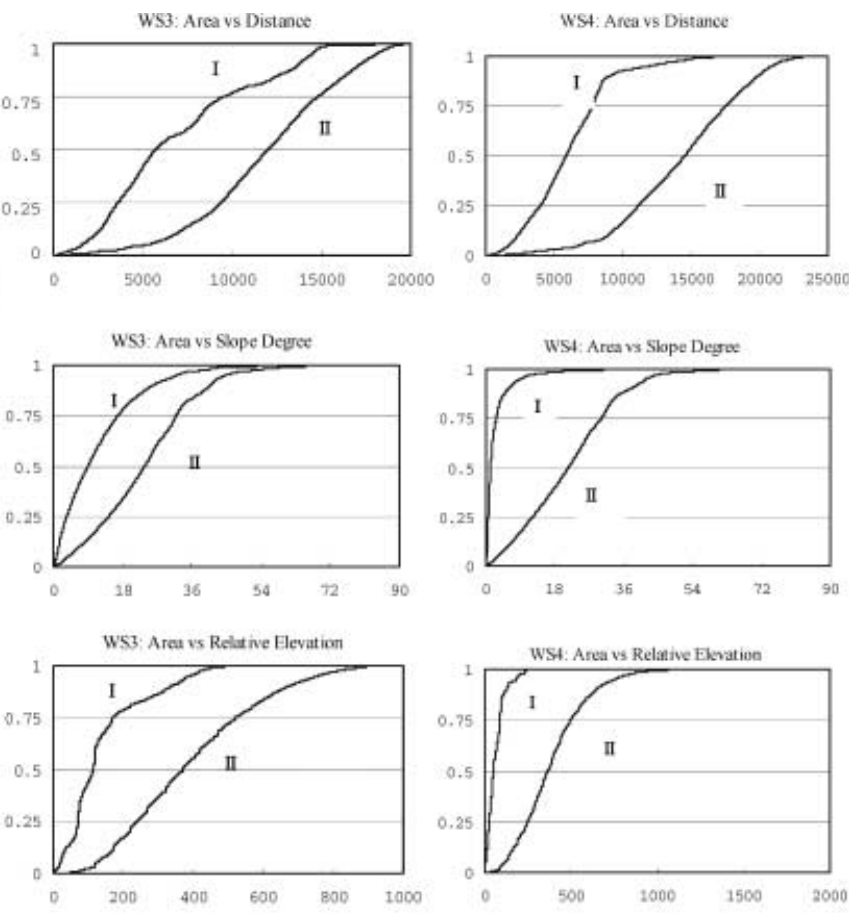
small areas, but differences are observed between the "source" and "sink" landscape types, concerning the spatial distribution of distance, slope degree, and relative elevation. In watershed 2, a big difference exists for spatial distribution between "source" and "sink" landscape types. The "source" landscapes are closer to the monitoring waterbodies than "sink" landscapes and are mainly distributed in the valley bottoms. In watershed 1, these two landscape types are located evenly throughout the whole watershed (Fig. 1).

Although both watersheds 3 and 4 are of larger size, obvious differences are observed in spatial distribution of "source" and "sink" landscape. As a whole, "source" landscape types are closer to the surface monitoring waterbody than "sink" landscape in both watersheds. However, it is more obvious in watershed 4 than in watershed 3 (Fig. 2). In watershed 4, "source" landscape is mostly concentrated in the low and flat areas with small relative elevation (Fig. 1).

\section{Spatial distribution of landscape units in different watersheds}

Figure 3 indicates that although watersheds 1 and 2 are both strip-shaped, the landscape SCIs, in regard to distance, slope degree, and relative elevation, are changeable with different area-percentage levels. As area percentage increases, the landscape SCI, with regard to distance, slope degree, and relative elevation, presents a stable increase in watershed 1 whereas in watershed 2 a decreasing trend is observed. Furthermore, at lower percentage levels, the three kinds of landscape SCIs in watershed 1 are lower than in watershed 2 but higher at higher percentage levels. The difference of SCIs in the two watersheds may explain to some extent the seasonal change of nitrogen concentration. Figure 3 shows the characteristics of three kinds of landscape SCIs in watersheds 3 and 4 . It can be observed that the three kinds of landscape SCIs in watershed 3 are obviously higher than those in watershed 4 .

\section{Dynamics of dissolved nitrogen concentration in surface water during a rainfall-deficit year} It was found from Table 2 that 1999 was a rainfall-deficit year $(359 \mathrm{~mm})$, while 2000 was nearly a rainfall-normal year $(636.5 \mathrm{~mm}$; a little lower than that in the rainfallnormal year). Figure 4 suggests that in a rainfall-deficit year the dynamic characteristics of nitrogen concentration in surface water are relatively consistent; i.e., rainy season $>$ normal rain season $>$ dry season, and their variation is small. As well, there is no clear difference in seasonal change for nitrogen concentration between dendritic river systems and strip-shaped river systems.

\section{Dynamics of nitrogen concentration in surface water during a rainfall-normal year}

The seasonal changes for dissolved nitrogen in surface water are different among the four different watersheds (Fig. 4). These can be divided into two categories.

1. Group 1: nitrogen concentration in the dry season is at its lowest value, and rises rapidly from dry season to rainy season, but not reaching the peak value until the mean-flow season. Further analysis shows that from dry to rainy season, nitrogen concentration for a dendritic river system (watershed 3) rises with a smaller range than for a strip-shaped river system. Then from the rainy to mean-flow season, the case is opposite. This group includes watersheds 1 and 3.

2. Group 2: the characteristic for this group is that nitrogen concentration is at the lowest value in the dry season, rises to its peak value in the rainy season, and falls sharply from rainy season to mean-flow season. Both from dry to rainy season and from rainy to meanflow season, nitrogen concentration changes greatly. This phenomenon occurs in watersheds 2 and 4.

\section{Discussion}

Effect of rainfall on nitrogen loss in surface water A comparison of nitrogen concentration during 1999 and 2000 shows us that nitrogen concentration in a rainfallnormal year is higher than that in a rainfall-deficit year. This is because irrigation is limited during the rainfall-deficit year, except for watershed 2. It reflects the
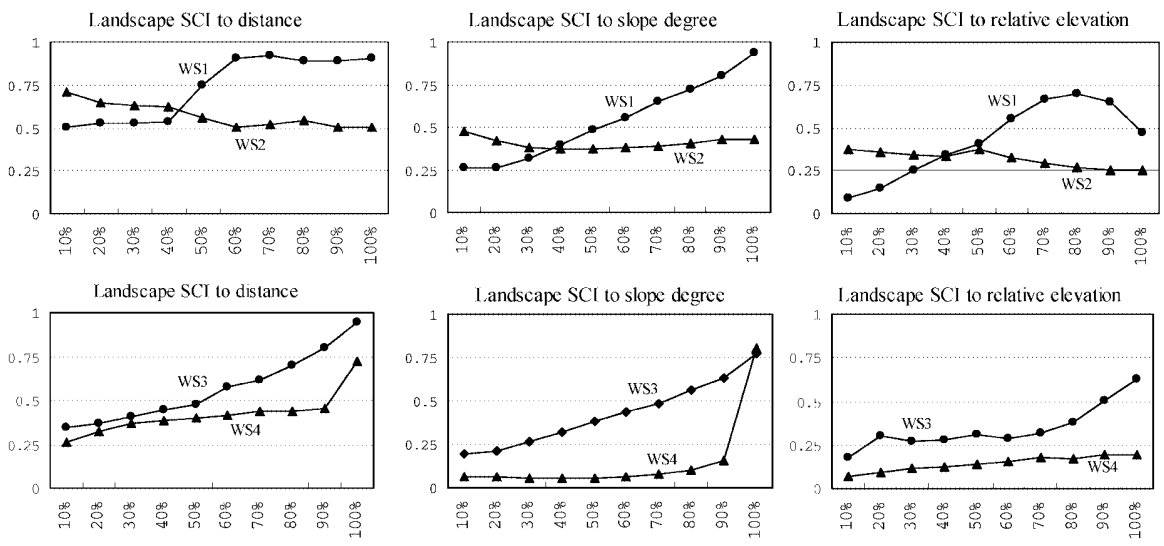

Fig. 3

Comparison of the three landscape SCIs in the four watersheds (WS) 
Table 2

Seasonal change of rainfall in Ziuhua region1

\begin{tabular}{|c|c|c|c|c|c|c|}
\hline \multirow[t]{2}{*}{ Month } & \multicolumn{2}{|l|}{ Mean rainfall } & \multicolumn{2}{|l|}{1999} & \multicolumn{2}{|l|}{2000} \\
\hline & $\begin{array}{l}\text { Monthly } \\
\text { rainfall (mm) }\end{array}$ & $\begin{array}{l}\text { Cumulative } \\
\text { rainfall }(\mathrm{mm})\end{array}$ & $\begin{array}{l}\text { Monthly } \\
\text { rainfall (mm) }\end{array}$ & $\begin{array}{l}\text { Cumulative } \\
\text { rainfall }(\mathrm{mm})\end{array}$ & $\begin{array}{l}\text { Monthly } \\
\text { rainfall (mm) }\end{array}$ & $\begin{array}{l}\text { Cumulative } \\
\text { rainfall }(\mathrm{mm})\end{array}$ \\
\hline January & 15.6 & 15.6 & 0.0 & - & 15.8 & - \\
\hline February & 13.2 & 28.7 & 0.0 & 0.0 & 0.0 & 15.8 \\
\hline March & 13.6 & 42.3 & 11.7 & 11.7 & 6.9 & 22.7 \\
\hline April & 9.9 & 52.3 & 50.3 & 62.0 & 19.2 & 41.9 \\
\hline May & 6.8 & 59.1 & 13.5 & 75.5 & 84.8 & 126.7 \\
\hline June & 7.5 & 66.6 & 71.3 & 146.8 & 44.9 & 171.6 \\
\hline July & 147.1 & 213.6 & 109.1 & 255.9 & 73.9 & 245.5 \\
\hline August & 322.4 & 536.0 & 14.6 & 270.5 & 278.0 & 523.5 \\
\hline September & 124.4 & 660.4 & 60.6 & 331.1 & 60.6 & 584.1 \\
\hline October & 37.4 & 697.8 & 0.8 & 331.9 & 47.6 & 631.7 \\
\hline November & 28.0 & 725.8 & 27.0 & 358.9 & 2.0 & 633.7 \\
\hline December & 22.2 & 748 & 0.3 & 359.2 & 2.80 & 636.5 \\
\hline
\end{tabular}

characteristics of nitrogen concentration in surface water under the influence of poor irrigation and low runoff. Due to this, a slight nitrogen loss appears. In rainfallnormal years, with abundant rainfall and increased irrigation, huge surface runoff and underground flow produce a strong effect on the surface-water quality. Particularly in the rainy season, nitrogen concentration rises remarkably compared with that in the dry season. In 2000, water samples during the rainy season were collected immediately after a heavy rainstorm. From these results, it can be found that soil erosion and runoff during rainstorm seasons has a strong effect on nutrient$\mathrm{N}$ transport and loss.

\section{Seasonal change of nitrogen concentration in surface water}

Two situations are observed: one is in the rainfall-deficit years when the seasonal change of nitrogen concentration is small, and the other one is in the rainfall-normal years when the seasonal change of nitrogen concentration is large (shown in Fig. 3).

1. Regarding situation 1, since the "source" landscape is spread over the whole watershed, the pollutant transported by surface runoff enters the monitored waterbody gradually. The dissolved nitrogen in surface water monitored immediately after the rainstorm is mainly from neighboring regions, which results in the nitrogen concentration rising slowly. Until the mean-flow season, it reaches the peak value when a huge influx of nonpoint-source pollutant from the whole watershed reaches the monitored waterbody.
2. In the other situation, as the "source" landscapes are located mainly nearby the monitoring point in watersheds 2 and 4, the pollutants induced by soil erosion and runoff may reach the monitored waterbody within a short period after rainstorms. Thus nitrogen concentration rises rapidly from the dry season to the rainy season, and then decreases rapidly from the rainy season to the mean-flow season when more clean runoff from the "sink" landscape in the upper part of the catchment enters the waterbody (Fig. 1).

\section{Effect of landscape types on nitrogen loss}

There is no obvious relationship between the relative landscape importance index in the watersheds and nitrogen concentration. This implies that the formation of nonpointsource pollution not only depends on the number of landscape types but also on the landscape pattern. In some cases, many "source" landscapes are in the watershed, but if most of them are located in the upper part in the watershed, the pollutant originating from these "source" landscapes may be detained when passing through the "sink" landscape.

Accordingly, the pollutants finally arriving at the monitored waterbody may be limited.

\section{Effect of landscape pattern on nitrogen loss}

Different landscape patterns in the watershed result in clear differences in nitrogen concentration in the surface water. A comparison of nitrogen concentration between the rainfall-deficit year and the rainfall-normal years indicates that the effect of watershed shape on the nitrogen loss is not obvious. Nitrogen loss is closely related to the

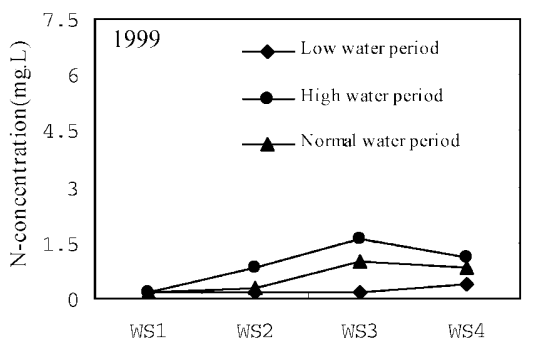

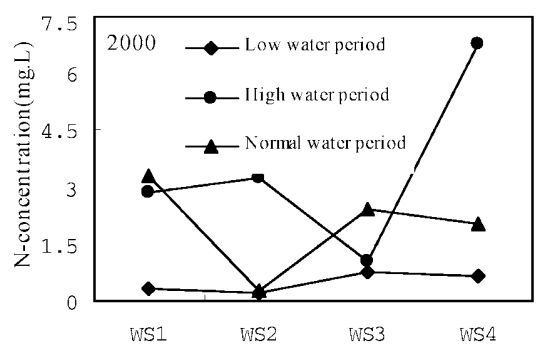

Fig. 4

Comparison of nitrogen-concentration dynamics in the different watersheds 
landscape pattern. Figures 3 and 4 suggest that there is a strong correlation between the landscape SCI to distance and nitrogen concentration in the rainy and mean-flow season in rainfall-normal years, and a weak correlation in the other seasons. Regarding the slope and the relative elevation SCI, there is no obvious relationship. Therefore, it implies that the distance of "source" and "sink" landscape from the waterbody plays an important role in the nitrogen loss.

\section{Conclusions}

Nonpoint-source pollution not only has a close correlation with fertilizer and pesticide application, irrigation, tillage, and topographical characteristics, but also has a close relationship with landscape patterns in a watershed. The landscape types in a region can be grouped into two categories: "source" and "sink" landscapes, based on their functions in the formation of nonpoint-source pollution. By contrasting four typical watersheds in terms of distinct landscape characteristics, this paper analyzes the seasonal change of nitrogen concentration in rainfall-deficit years and rainfall-normal years, and the relationship between nitrogen concentration, watershed shape, and landscape pattern. The following conclusions can be made.

1. Nitrogen concentration in the rainfall-normal years is higher than that in the rainfall-deficit years. This shows that surface runoff and the underground flow during the rainy season has a strong effect on nonpoint-source pollutant loss and transport.

2. In the rainfall-deficit year, the seasonal and spatial change of nitrogen concentration in surface water is limited, while it is large in the rainfall-normal years. For watersheds where "source" landscape types are located near the surface waterbody, nitrogen concentration is lowest during the dry season and rises remarkably in the rainy season; then it decreases rapidly from the rainy season to the mean-flow season. However, for watersheds where "source" landscape types are spread over the whole watershed, nitrogen concentration is relatively low during the dry season and rises continually in the rainy season; but it does not reach a peak value until the mean low season.

3. There is no clear relationship between the relative-importance index of landscape types, the nitrogen concentration in surface water, and watershed shape. However, the spatial pattern of "source" and "sink" landscapes plays an important role in nitrogen loss in a heterogeneous landscape.

Acknowledgements This article is the partial result of a key project supported by the National Natural Science Foundation of China (contract no.: 49831020) and fundamental project (49971072). It is also supported by National Natural Science Foundation of China (49725101) and partly funded by Knowledge Innovation Program (KIP) of the Chinese Academy of Sciences (RCEES9903; RCEES99008).

\section{References}

Alm AL (1990) Nonpoint-sources of water pollution. Environ Sci Technol 24(7):967

Chen Liding, Fu Bojie (2000) Farm ecosystem management and control of nonpoint-source pollution (in Chinese). Environ Sci 21(2):98-100

Chen Liding, Wang Jun, Fu Bojie, Qiu Yang (2001) Land-use change in a small catchment of northern Loess Plateau, China. Agric Ecosys Environ 86(2):163-172

Ebbert JC, Kim MH (1998) Soil processes and chemical transport. J Environ Qual 27:372-380

Fu Bojie (1995) Landscape diversity analysis and mapping (in Chinese). Acta Ecol Sin 15(4):345-350

Fu Bojie, Ma Keming, Zhou Huafeng, Chen Liding (1999) The effect of land use structure on the distribution of soil nutrients in the hilly area of the loess plateau, China. Chin Sci Bull 44(8):732-736

Gilliland MW (1987) A geographical information system to predict nonpoint-sources pollution potential. Water Resour Bull 23(2):281-291

He Chansheng, Fu Bojie, Chen Liding (1998) Nonpoint-source pollution control and management (in Chinese). Environ Sci 19(5):87-91

Heathwaite L, Sharpley A, Giburek W (2000) A conceptual approach for integrating phosphorus and nitrogen management at watershed scales. J Environ Qual 29(1):158-166

Heng HH, Nikolaidis NP (1998) Modeling of nonpoint-source pollution of nitrogen at the watershed scale. J Am Water Resour Assoc 34(2):359-374

Istvanovics V, Somlyody L (2001) Factors influencing lake recovery from eutrophication - the case for basin of lake Balaton. Water Res 35(3):729-735

Knisel WG (ed) (1980) CREAMS: a field scale model for chemicals, runoff and erosion from agricultural management system. Agricultural Research Service, USDA, Report No 26, Washington, DC

Leon LF, Soulis ED, Kouwen N, Farquhar GJ (2001) Nonpointsource pollution: a distributed water quality modelling approach. Water Res 35(4):997-1007

Leonard RA, Knisel WG, Sull DA (1987) Gleams: groundwater loading effects of agricultural management systems. Trans ASAE 30(5):1403-1418

Li Junran, Chen Liding, Guo Xudong, Fu Bojie (2000) Effect of land-use structure on nonpoint-source pollution (in Chinese). China Environ Sci 20(6):506-511

Li Xiuzhen, Xiao Duning, Hu Yuanman, Wang Xianli (2001) Effect of wetland landscape pattern on nutrient reduction in the Liaohe Delta (in Chinese). Acta Geogr Sin 56(1):32-133

Line DE, Osmand DL, Coffey SW, Arnold JA, Gale JA, Spooner J, Jennings GD (1994) Nonpoint-sources. Water Environ Res 66(4):585-601

Line DE, McLaughlin RA, Osmond DL, Jennings GD, Harman WA, Lombardo LA, Spooner J (1998) Nonpoint-sources pollution. Water Environ Res 70(4):895-911

Mankin KR, Koelliker JK, Kalita PK (1999) Watershed and lake water quality assessment: an integrated modeling approach. J Am Water Resour Assoc 35(5):1069-1079

Nikolaidis NP, Heng H, Semagin R, Clausen JC (1998) Non-linear response of a mixed land use watershed to nitrogen loading. Agric Ecosys Environ 67(3):251-265

O’Neill RV, Krummel JR, Gardner RH, Sugihara G, Jackson B, DeAngelis DL, Milne BT, Turner MG, Zygmunt B, Christensen SW, Dale VH, Graham RL (1988) Indices of landscape pattern. Landscape Ecol 1:153-162

Pearce MC (1992) Pattern analysis of forest cover in southwestern Ontario. East Lakes Geogr 27:65-76 
Pearce RA, Trilica MJ, Leijinger WC, Smith JL, Frasier GW (1997) Efficiency of grass buffer strips and vegetation height on sediment filtration in laboratory rainfall simulation. J Environ Qual 26:139-144

Peterjohn WT, Correll DL (1984) Nutrient dynamics in an agricultural watershed: observations on the role of a riparian forest. Ecology 65:1466-1475

Sliva L, Williams DD (2001) Buffer zone versus whole catchment approaches to studying land use impact on river water quality. Water Res 35(14):3462-3472

Stow CA, Borsuk ME, Stanley DW (2001) Long-term changes in watershed nutrient inputs and river exports in the Neuse River, North Carolina. Water Res 35(6):1489-1499

Troiano J, Garretson C, Krauter C, Brownell J, Huston J (1993) Influence of amount and method of irrigation water application on leaching of Atrazine. J Environ Qual 22:290-298

Wang Gang, Guo Baiquan (1999) Analysis of the present water body status and the countermeasures of pollution control of Yuqiao Reservoir (in Chinese). Urban Environ Life 12(2):27-28

Wang Guoxiang, Pu Peimin, Zhang Shengzhao, Li Wanchun, $\mathrm{Hu}$ Weiping, Hu Chunhua (1998) The purification of an artificial complex ecosystem for local water in Taihu Lake (in Chinese). China Environ Sci 18(5):410-414

Yan M, Kahawita R (2000) Modelling the fate of pollutant in overland flow. Water Res 34(13):3335-3344

Yin C, Zhao M, Jin W, Lan Z (1993) A multi-pond system as a protective zone for the management of lakes in China. Hydrobiologia 251:321-329

Young RA, Onstad CA, Bosch D, Anderson WP (1989) AGNPS, a nonpoint-source pollution model for evaluating agricultural watersheds. J Soil Water Conserv 44:168-173

Zhang Shuilong, Zhuang Ji (1998) Trend and current situation of agricultural nonpoint-source pollution (in Chinese). J Ecol 17(6):51-55 